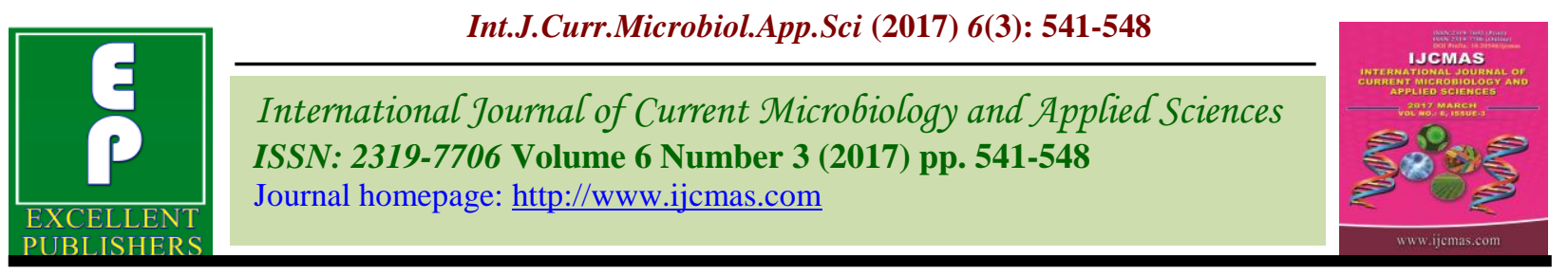

Original Research Article

https://doi.org/10.20546/ijcmas.2017.603.063

\title{
Biology and Bionomics of Zig Zag Beetle Cheilomenes sexmaculatus Fabricius (Coleoptera: Coccinellidae)
}

\author{
V. Shanmugapriya ${ }^{1^{*}}$, C.M. Muralidharan ${ }^{2}$ and K. Karthick ${ }^{3}$ \\ ${ }^{1}$ Department of Agricultural Entomology, C.P. College of Agriculture, S.D. Agricultural \\ University, Sardarkrushinagar, Gujarat - 385506, India \\ ${ }^{2}$ Department of Agricultural Entomology, Date palm Research Station, S.D. Agricultural \\ University, Mundra, Kachchh, Gujarat - 370421, India \\ ${ }^{3}$ Department of Vegetable Science, College of Horticulture, S.D. Agricultural University, \\ Jagudan, Gujarat - 382710, India \\ *Corresponding author
}

\begin{tabular}{|c|c|}
\hline & A B S T R A C T \\
\hline $\begin{array}{l}\text { Biology, } \\
\text { Bionomics, } \\
\text { Cheilomenes } \\
\text { sexmaculatus, } \\
\text { Lipaphis erysimi. }\end{array}$ & \multirow{3}{*}{$\begin{array}{l}\text { Biology and bionomics of Cheilomenes sexmaculatus on Lipaphis erysimi was } \\
\text { investigated under laboratory conditions during 2013. Biology of C. sexmaculatus on } \\
\text { Lipaphis erysimi revealed the presence of four instars, which lasted for of } 7.16 \pm 0.99 \\
\text { days. The eggs hatched within } 1-3 \text { days. The total life span of male and female were } 16.44 \\
\pm 1.19 \text { days and } 22.04 \pm 2.42 \text { days, respectively. The mean pupal period lasted for } 5.88 \pm \\
0.73 \text { days. The fecundity of the female was } 323.52 \pm 24.80 \text { eggs / female. The study on } \\
\text { bionomics indicated a progressive increase in length and breadth of various stages after } \\
\text { each moulting except for pupae. The average length and breadth of the eggs were } 1.02 \pm \\
0.04 \text { mm and } 0.39 \pm 0.01 \text { mm respectively. The average length and breadth of a full grown } \\
\text { grub varied from an average of } 6.78 \pm 0.30 \mathrm{~mm} \text { and } 1.83 \pm 0.05 \text { mm respectively. The } \\
\text { average body length of male was } 6.07 \pm 0.31 \mathrm{~mm} \text {, where as the body length of female was } \\
6.29 \pm 0.45 \text { mm. Four different colour morphs (orange, light red, black and yellow) were } \\
\text { noticed in the field. }\end{array}$} \\
\hline Article Info & \\
\hline $\begin{array}{l}\text { Accepted: } \\
\text { 10 February } 2017 \\
\text { Available Online: } \\
10 \text { March } 2017\end{array}$ & \\
\hline
\end{tabular}

\section{Introduction}

Coccinellids are beneficial insects because of their predaceous nature. These insects are considered as the most economical and eco friendly alternatives of the hazardous pesticides. The important role of coccinellids in the biological control programme has rendered this group of insects of great practical and scientific interest as majority of them are predacious both in larval and adult stages. Cheilomenes sexmaculatus (Fabricius) is one of the potential predators of aphids and it is widely distributed in India, Iran, Australia and other parts of the Oriental region (Agarwala and Bardhanroy, 1997). The important features of $C$. sexmaculatus includes its wide geographic distribution and host range, broad habitats, tolerance to certain pesticides, enhanced searching ability, voracious larval feeding capacity and easy rearing in laboratory (Venkatesan et al., 2006). The development and feeding potential of coccinellids varies with their food and 
changes with the environmental conditions. Therefore, the study was undertaken to determine the biology and bionomics of $C$. sexmaculatus on the most important aphid host of North Gujarat, viz., L. erysimi (Kaltenbach).

\section{Materials and Methods}

Initial culture of the beetle was collected from different crops from S.D. Agricultural University campus during October November 2013 and kept in small rearing cages $(30 \times 30 \times 30 \mathrm{~cm})$ and reared on $L$. erysimi. The study was carried out at room temperature 22 to $28.5^{\circ} \mathrm{C}$ (av: $25.12 \pm 1.68^{\circ} \mathrm{C}$ ) and relative humidity 66 to 74.5 (68.58 \pm 4.28) per cent. Freshly laid eggs of $C$. sexmaculatus were collected from the rearing cage every day from the initial date of oviposition up to the cessation of egg laying. Parameters like length, breadth, the incubation period as well as hatching percentage of the eggs was also recorded. Number of grub instars along with its duration was determined on the basis of exuviae casted-off by the grubs. Observations on measurements of length and breadth were recorded instar-wise. Pupae were separated and kept in individual vials for adult emergence. Pupal period was calculated by date of pupation to date of adult emergence. Newly emerged adults of $C$. sexmaculatus were confined in rearing cage in pairs and provided with $L$. ersyimi as food. Laboratory reared adults were separated as male and female based on their body size and external genitalia. The last abdominal segment was entire or notched in males and narrowly and rounded or medially divided in case of females. Longevity of males and females were studied separately. Similarly, fecundity, pre-oviposition, oviposition, post-oviposition periods of females and sex-ratio (male: female) for laboratory culture were also recorded. For the purpose, twenty five pairs of
C. sexmaculatus were kept individually and data were recorded. Eggs laid by each female were counted daily in the morning and total number of eggs laid during entire adult period was considered as fecundity. The time after emergence of adult from pupae and starting of oviposition was considered as pre-oviposition period. The period of egg laying was considered as oviposition period. Post oviposition period of female was recorded as period between the days of female ceased egg-laying to the day of death.

\section{Results and Discussion}

The results of biological parameters and bionomics of $C$. sexmaculatus reared on mustard aphid, L. erysimi was presented in table 1 .

\section{Eggs}

The eggs were laid in clusters (Fig. 1) which were pale to bright yellow in colour, turned into dark yellow before hatching. A data depicted in table 1 indicated that the size of the eggs varied from 0.87 to $1.21 \mathrm{~mm}$ with an average of $1.02 \pm 0.04 \mathrm{~mm}$. The breadth of eggs varied from $0.32-0.45 \mathrm{~mm}$ with a mean value of $0.39 \pm 0.01 \mathrm{~mm}$. The number of eggs per cluster varied from 45 to 69 with a mean value of $53.2 \pm 6.39$

\section{Incubation period}

An incubation period of $1-3$ days with an average of $1.48 \pm 0.54$ days was observed under laboratory conditions. Tank and Korat (2007) observed an incubation period of $1-2$ days with an average of $1.40 \pm 0.66$ days, which collaborate with the present findings. However, Jat et al., (2009) revealed a mean incubation period of 9.28 days, when reared up on barley aphid. The difference may be due to the influence of different hosts and rearing conditions on the predator. 
The per cent hatching under laboratory conditions varied from $68-84$ per cent (av. $77.2 \pm 5.43$ ) which was in accordance with the findings of Zala (1995) who observed a hatching percentage of eggs varied from 80 to 86.67 with an average of 82.85 when reared on L. erysimi. However, there was a variation when compared with the reports of Varma et al., (1993), where observed the percentage egg hatching was $93.4 \%$ on C. sexmaculatus.

\section{Grubs}

The duration and measurements of various instars of $C$. sexmaculatus is presented in table 1 and 2. A perusal of the data given in the table 1 and 2 indicated that there are four instars in the life cycle of $C$. sexmaculatus. Grubs were dark blackish grey to brown in colour with yellowish patches on dorsal side. The young grubs of $C$. sexmaculatus were black with long legs, body tapering to the hind end as it grows older, white spots appeared and the full grown larvae were black with yellow and white blotches. When the eggs hatched into grubs it undergoes metamorphosis three times with four larval instars to become a full grown grub and then it enters the pupal stage (Fig. 1).

The duration of I instar grub was $1-3$ days with an average of $1.88 \pm 0.73$ days under laboratory conditions. The body length and breadth ranged from 1.12 to $1.91 \mathrm{~mm}$ and 0.42 to $0.59 \mathrm{~mm}$ with an average of $1.41 \pm$ 0.22 and $0.49 \pm 0.05$ respectively. The II instar stage of $C$. sexmaculatus lasted about 1 -3 days with a mean duration of $1.76 \pm 0.60$ days. The length and breadth of the II instar ranged from $4.12 \mathrm{~mm}$ to $5.45 \mathrm{~mm}$ and 1.53 $\mathrm{mm}$ to $1.78 \mathrm{~mm}$ with an average of $4.74 \pm$ $0.34 \mathrm{~mm}$ and $1.64 \pm 0.06 \mathrm{~mm}$ respectively. The duration of III instar grubs varied from 1 -3 days with a mean duration of $1.6 \pm 0.58$ days. The linear measurements of length and breadth varied from $5.16 \mathrm{~mm}$ to $7.13 \mathrm{~mm}$ and $1.72 \mathrm{~mm}$ to $1.86 \mathrm{~mm}$ respectively, with a mean value of $6.03 \pm 0.72 \mathrm{~mm}$ and $1.78 \pm$ $0.04 \mathrm{~mm}$ respectively. The grub period for IV lasted about $1-3$ days with a mean duration of $1.92 \pm 0.70$ days. The length varied from $6.33 \mathrm{~mm}$ to $7.3 \mathrm{~mm}$ with an average of $6.78 \pm$ $0.30 \mathrm{~mm}$. The breadth of the fourth instar grub varied from $1.75 \mathrm{~mm}$ to $1.92 \mathrm{~mm}$ with a mean of $1.83 \pm 0.05 \mathrm{~mm}$.

The biology of $C$. sexmaculatus was studied by various workers on different hosts. According to Varma et al. (1993), the total larval duration was $7.4 \pm 1.0$ days with 4 larval instars lasting $1.4 \pm 0.2,1.3 \pm 0.3$ and $3.4 \pm 0.8$ days respectively. Same observation were also reported by Patel (1998) and Tank and Korat (2007).

\section{Pupae}

Pupation takes place on the leaf, the larva undergoes pupation by fixing itself by the tail. When grubs were about to pupate, they turn dark brown in colour attached itself either or upper or lower surface or sometimes even on stems. Black spots were established symmetrically on the segments of fully formed pupae (Fig. 1).

The data in table 1 and 2 indicated a pupal stage, lasting 1-3 days with an average of $5.88 \pm 0.73$ days. A pupal period of 3.83 days (Rajamohan \& Jayaraj, 1979), 2.98 days (Patel, 1985), 2.6 days (Varma et al., 1993) 2.68 days (Rai et al., 2003) have been recorded in the past which is in close conformity with present observations.

\section{Adult}

The adult beetles were oval in shape, elongated and moderately convex from dorsal side (Fig. 1). Elytra had six black macular including two zig-zag lines in colour, enclosing hind pair of wings. Abdomen and eyes were yellow in colour. 
Table.1 Duration of different life stages of M. sexmaculatus on mustard aphid, L. erysimi

\begin{tabular}{|c|c|c|c|}
\hline \multirow[t]{2}{*}{ Criteria } & \multicolumn{3}{|c|}{ Duration (days) } \\
\hline & Minimum & Maximum & Mean \\
\hline Eggs $(n=25)$ & 1 & 3 & $1.48 \pm 0.59$ \\
\hline \multicolumn{4}{|l|}{ Grubs (n = 25) } \\
\hline I instar & 1 & 3 & $1.88 \pm 0.73$ \\
\hline II instar & 1 & 3 & $1.76 \pm 0.60$ \\
\hline III instar & 1 & 3 & $1.6 \pm 0.58$ \\
\hline IV instar & 1 & 3 & $1.92 \pm 0.70$ \\
\hline Total & 4 & 9 & $7.16 \pm 0.99$ \\
\hline Pupa $(n=25)$ & 4 & 7 & $5.88 \pm 0.73$ \\
\hline \multicolumn{4}{|l|}{ Adult(n = 25) } \\
\hline Male & 13 & 18 & $16.44 \pm 1.19$ \\
\hline Female & 17 & 31 & $22.04 \pm 2.42$ \\
\hline Pre ovipostion & 2 & 12 & $3.88 \pm 1.88$ \\
\hline Oviposition & 16 & 38 & $22.96 \pm 3.54$ \\
\hline No. of egg clusters/ female & 4 & 6 & $4.8 \pm 1.23$ \\
\hline No. eggs/ cluster $(n=10)$ & 45 & 69 & $53.2 \pm 6.39$ \\
\hline Hatching percentage $(\mathrm{n}=10)$ & 68 & 84 & $77.2 \pm 5.43$ \\
\hline Post oviposition & 2 & 5 & $3.36 \pm 1.04$ \\
\hline \multicolumn{4}{|l|}{ Entire life span $(n=25)$} \\
\hline Male & 23 & 41 & $35.2 \pm 3.77$ \\
\hline Female & 23 & 43 & $40.32 \pm 3.98$ \\
\hline Fecundity $(n=10)$ & 257 eggs & 386 eggs & $323.52 \pm 24.80$ \\
\hline Sex ratio(F:M) & \multicolumn{3}{|c|}{$1: 1.35$} \\
\hline
\end{tabular}

Table.2 Measurement of different stages of $C$. sexmaculatus

\begin{tabular}{|c|c|c|c|c|c|c|}
\hline \multirow{2}{*}{ Stage } & \multicolumn{3}{|c|}{ Length (mm) } & \multicolumn{3}{|c|}{ Breadth $(\mathrm{mm})$} \\
\hline & Min & Max & Mean & Min & Max & Mean \\
\hline Egg & 0.87 & 1.21 & $1.02 \pm 0.04$ & 0.32 & 0.45 & $0.39 \pm 0.01$ \\
\hline \multicolumn{7}{|c|}{ Grub } \\
\hline I instar & 1.12 & 1.91 & $1.41 \pm 0.22$ & 0.42 & 0.59 & $0.49 \pm 0.05$ \\
\hline II instar & 4.12 & 5.25 & $4.74 \pm 0.34$ & 1.53 & 1.78 & $1.64 \pm 0.06$ \\
\hline III instar & 5.16 & 7.3 & $6.03 \pm 0.72$ & 1.72 & 1.86 & $1.78 \pm 0.04$ \\
\hline IV instar & 6.33 & 7.3 & $6.78 \pm 0.30$ & 1.75 & 1.92 & $1.83 \pm 0.05$ \\
\hline Pupa & 3.94 & 5.65 & $4.80 \pm 0.54$ & 2.44 & 3.38 & $2.92 \pm 0.25$ \\
\hline \multicolumn{7}{|c|}{ Adult } \\
\hline Male & 5.62 & 6.54 & $6.07 \pm 0.31$ & 3.55 & 5.36 & $4.54 \pm 0.60$ \\
\hline Female & 5.59 & 7.14 & $6.29 \pm 0.45$ & 4.6 & 5.79 & $4.97 \pm 0.35$ \\
\hline
\end{tabular}


Fig.1 Biology of C. sexmaculatus
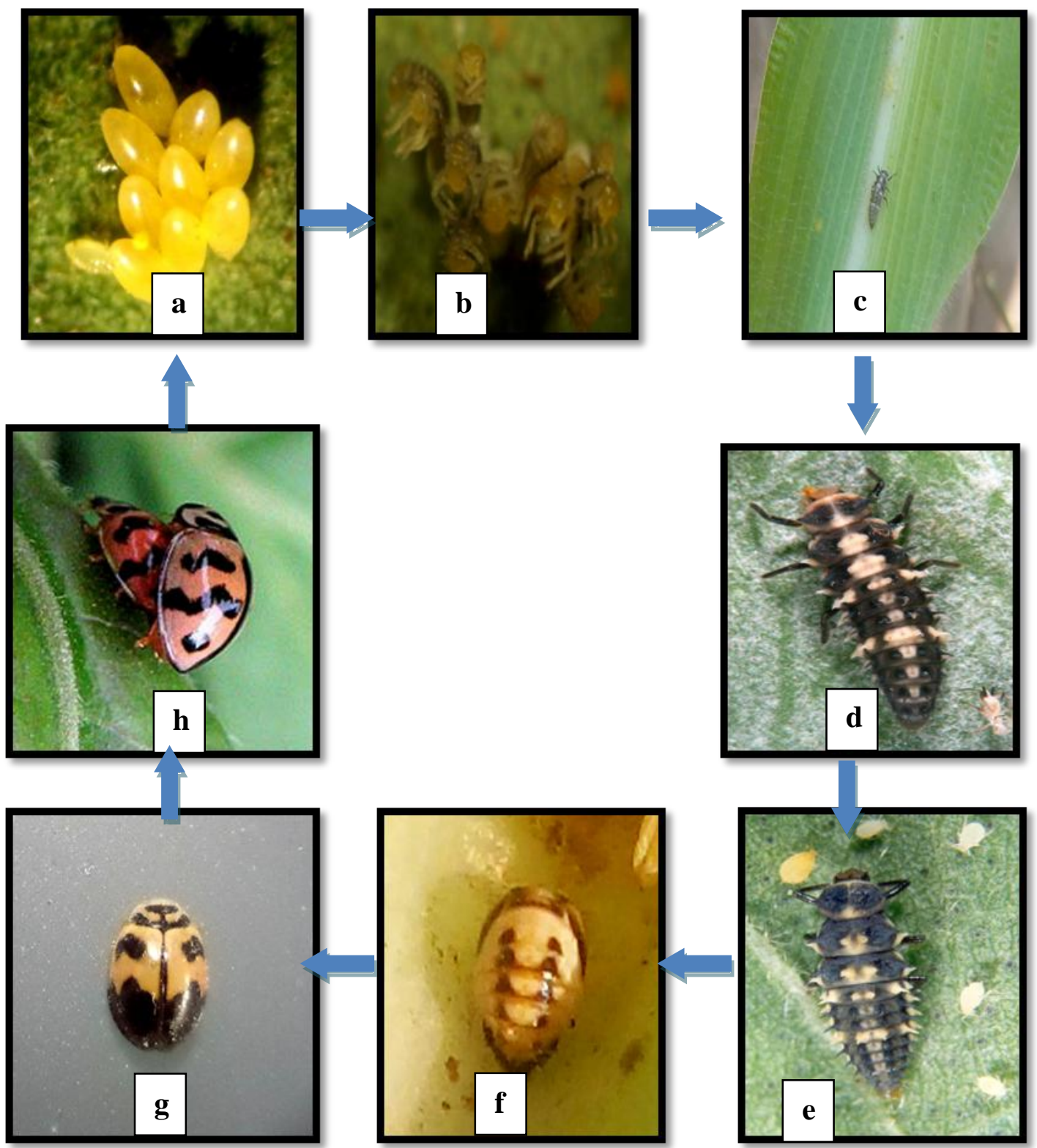
a)Eggs
b) I instar
c) II instar
f) Pupa
g) Adult
h) Mating

d) III instar

e) IV instar 
Fig.2 Colour morphs of C. sexmaculatus
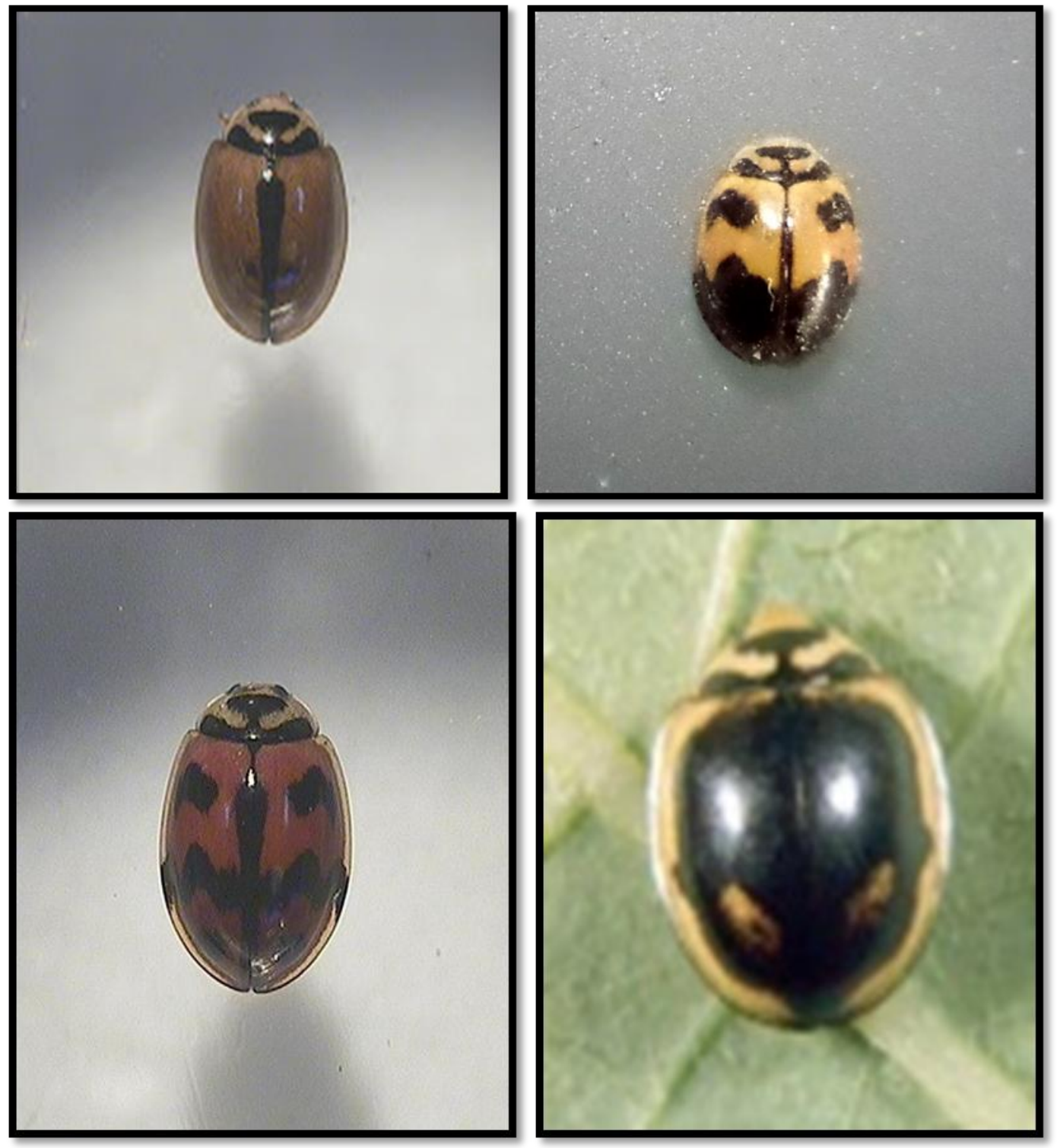

The elytra and pronotum were marked with zig - zag markings. Four different colour morphs (orange, light red, black and yellow) were noticed in the field (Fig. 2). Male and female adult beetles can be differentiated on the basis of body size and structure of external genitalia. The last abdominal segment was entire or notched to some degrees in males and it was narrow or evenly rounded or medially divided or rounded in case of females. The data depicted in the table 1 indicated that the male lasted for $13-8$ days with an average life span of $16 \pm 1.19$ days, where as female survived longer with an average life span of $22.04 \pm 2.42$ days. The body length of male varied from $5.62 \mathrm{~mm}$ to $6.54 \mathrm{~mm}$ with an average of $6.07 \pm 0.31 \mathrm{~mm}$, where as the body length of female varied from 5.59 to $7.14 \mathrm{~mm}$ with an average of 6.29 $\pm 0.45 \mathrm{~mm}$ indicating its bigger size. The width of male ranged from $3.55 \mathrm{~mm}$ to 5.36 $\mathrm{mm}$ with an average of $4.54 \pm 0.60 \mathrm{~mm}$ where as the females was slightly wider, with an average width of $4.97 \pm 0.35 \mathrm{~mm}$. According 
to Zala (1995), the longevity of male and female were 16.2 and 20.21 days respectively. Tank (2006), reported a mean survival period for male and female as $20.23 \pm 2.80$ and 16.09 \pm 2.54 days respectively.

In the present study we have observed a longer life span for female $C$. sexmaculatus is in fully agreement with earlier workers. Sureja (1991) reported the average length and breadth of male as 4.75 and $3.60 \mathrm{~mm}$, where 3.69 and $3.08 \mathrm{~mm}$ for female. The observation of Zala (1995) indicated an average length and breadth of male on 4.21 and $3.88 \mathrm{~mm}$, where as 5.06 and $4.19 \mathrm{~mm}$ for female which were in collaboration with our findings.

\section{Fecundity}

Female laid eggs in clusters. In our study we observed a pre oviposition period of 2 to 12 days with an average of $3.88 \pm 1.88$ days (table 1). The oviposition period lasts about $16-38$ days with an average of $22.96 \pm 3.54$ days and a short post oviposition period of 2 to 5 days (Average $3.36 \pm 1.04$ ). The number of eggs laid by the female varied 257 to 386 eggs with an average of $323.52 \pm 24.80 \mathrm{eggs} /$ female. Sureja (1991) revealed that average number of eggs laid by female was 574 eggs when reared on L. erysimi. An average fecundity of $366 \pm 97.9$ was also reported by Verma et al., (1993). The occurrence of color morphs was also observed by Sandeep and Sharma (2010) which collaborates with present observations.

\section{Sex ratio}

A sex ratio of 1:1.35 was observed in laboratory reared adults which is slightly towards female. Many earlier reports indicated varying sex ratio in laboratory reared and field collected adults. Patel (1985), $1: 1.32$ and 1:1.59 (laboratory and fields respectively), 1:1.68 and 1:1.50 (Zala, 1995),
1:1.43 and 1:1.35 (Tank, 2006) indicated both in field as well as laboratory reared population sex ratio in slightly towards to female, which confirm the present observations.

\section{Entire life span}

A perusal of the data depicted in table 1 indicated that the entire life period of male varied from 23 to 41 days (Av: $35.2 \pm 3.72$ days ) whereas it was 23 - 43 days for female, indicating females survived more, compared to males. The entire life span reported by earlier workers, (Patel, 1985; Zala, 1995; Patel, 1998 and Tank, 2006) were almost similar, however slight variation observed may be due to rearing conditions and host insect. Hence the present findings are in agreement with earlier findings.

\section{References}

Agarwala, B.K. and Bardhanroy, P. 1997. Oviposition behavior and reproduction efficiency in ladybird beetles (Coccinellidae: Coleoptera): A case study of Menochilus sexmaculatus (Fabricius). J. Aphidol., 11: 49-59.

Jat, H., Swaminathan, R. and Upadhyay, B. 2009. Bio-ecology of aphidophagous coccinellids in maize-sorghum based cropping system. Indian J. Entomol., 71(2): 170-185.

Patel, P.V. 1985. Bionomics and predatory capacity of lady bird beetle Menochilus sexmaculatus Fab. along with its relative susceptibility to certain insecticides. M.Sc. Agri.) thesis submitted to Gujarat Agricultural University, Sardarkrushinagar.

Patel, D.P. 1998. Bionomics and predatory potential of Menochilus sexmaculatus Fab. and Chrysoperla carnea Steph. reared on maize aphid Rhopalosiphum maidis Fitch along with their 
comparative susceptibility to some neem based pesticides. (M.Sc. Agri.) thesis submitted to Gujarat Agricultural University, Sardarkrushinagar.

Rai, M.K., Ramamurthy, V.V. and Singh, P.K. 2003. Observations on the biology of the coccinellid predator, Cheilomenes sexmaculata (Fab) on Aphis craccivora. Annals of Plant Protection Sci., 11(1): 7-10.

Rajamohan, N. and Jayaraj, S. 1974. Studies on the reproduction of the coccinellid M. sexmaculatus on four species of aphids. Zeitchrift fur Angewadte Entomologie, 74(4): 388-393.

Sandeep Singh and Sharma, D.R. 2010. Coccinellid predators beetles of insect pests of citrus in the Indian Punjab. Crop Improvement, 37(2): 207

Sureja, B.V. 1991. Bioecology and utilization of predatory coccinellids for the management of aphid. PhD. thesis submitted to Rajasthan Agricultural University, Udaipur.

Tank, B.D. 2006. Carry-over and biology of ladybird beetle, Cheilomenes sexmaculata Fab. under middle Gujarat conditions. M.Sc. Agri.) thesis submitted to Anand Agricultural University, Anand.

Tank, B.D. and Korat, D.M. 2007. Biology of ladybird beetle, Cheilomenes sexmaculata Fab. in middle Gujarat conditions. Karnataka J. Agri. Sci., 20(3): 634-636.

Venkatesan, T., Jalali, S.K., Murthy, K.S. and Bhaskaran, T. 2006. Rearing of Cheilomenes sexmaculata (Fabricius) on artificial diet and its predatory efficiency against Aphis craccivora Koch. Annals of Plant Protection Sci., 14(2): 277-279.

Verma, S.N., Gargav, V.P. and Mittal, S. 1983. Host preference of six spotted ladybird beetle, Menochilus sexmaculatus Fab. Indian J. Plant Protection, 11: 66 - 69.

Zala, A.P. 1995. Studies on bionomics and predatory potential of Menochilus sexmaculatus Fab. reared on mustard aphid Lipaphis erysimi Kalt along with its seasonal fluctuations and tolerance to some insecticides. M.Sc. Agri.) thesis submitted to Gujarat Agricultural University, Sardarkrushinagar.

\section{How to cite this article:}

Shanmugapriya, V., C.M. Muralidharan and Karthick, K. 2017. Biology and Bionomics of Zig Zag Beetle Cheilomenes sexmaculatus Fabricius (Coleoptera: Coccinellidae). Int.J.Curr.Microbiol.App.Sci. 6(3): 541-548. doi: https://doi.org/10.20546/ijcmas.2017.603.063 